\title{
Conceptualising Authentic Mobile Learning
}

Kevin Burden

Faculty of Education, The University, Kingston-upon-Hull, UK

Cottingham Road, Hull, HU6: k.j.burden@hull.ac.uk

Matthew Kearney

Centre for Research in Learning and Change, University of Technology, Sydney (UTS), NSW, Australia: Matthew.Kearney@uts.edu.au 


\title{
Conceptualising Authentic Mobile Learning
}

\begin{abstract}
Conventional accounts of authentic learning focus on contextual factors: tasks, processes, how situated the learning is and the extent to which learners engage in simulated or participative real-world activities. This paper theorises how ubiquitous mobile technologies are fracturing the boundaries that demarcate traditional accounts of authentic learning affording new opportunities to reconceptualise what authenticity means for learners when they use a boundary object such as a mobile device. Whilst some of this has been captured previously with terms like 'seamless', 'contextualised' and 'agile' learning this paper argues that the concept of authentic mobile learning is a highly fluid construct which will continue to change as the technologies develop and as the pedagogical affordances become better understood by educators and end-users. The paper offers a three-dimensional model of authentic mobile learning and argues that further empirical research is required to understand what is authentic mobile learning from the perception of learners.
\end{abstract}

Keywords: authentic learning; mobile learning; situated learning

\section{Introduction}

'authenticity remains a concept that is referred to by many, yet poorly defined'

(Barab, Squire, and Dueber, 2000, p.38)

Contemporary endeavours to understand and define mobile learning (m-learning) draw attention to the situated and seamless nature of activities that are mediated through the affordances of mobile technologies, describing these as authentic learning (Herrington \& Kervin, 2007; Herrington, Mantei, Herrington, Olney \& Ferry, 2008). Learners are considered to be more engaged in contexts which offer high levels of personal significance and cultural relevance. In terms of personal significance they act as a bridge linking new information and theories to learners' life worlds outside of formal education and in terms of cultural relevance they enculturate the learner into the practices of the community helping them to think like a member of the discipline (Lombardi, 2007; Meyers \& Nulty, 2009; Stein, Isaacs \& Andrews, 2004). Despite considerable research associated with authentic learning (Barab, Squire \& Dueber, 
1989; Browns, Collins and Duguid, 1989; CTVG, 1990; Petraglia, 1998; Radinsky, Bouillion, Lento \& Gomez, 2001), there are to date relatively few studies which have analysed how mobile technologies support and enhance authentic learning and reciprocally how far authenticity is an inherent characteristic of mobile learning itself (Herrington \& Kervin, 2007; Herrington, et al 2008; Kearney, Schuck, Burden \& Aubusson, 2012; Kearney, Burden \& Rai, 2015).

Recent data, collected by the authors from an international survey of educators using mobile technologies in their teaching and learning, highlights one of many confusions associated with the twin concepts of authenticity and mobile learning. Participants consistently ranked the construct of authenticity as 'high', with a mean average of 2.4 on a scale of 1 (low) to 3 (high), when describing a learning scenario where they had used mobile technologies for pedagogical purposes. This high ranking of authenticity by the teachers was despite the fact that $82 \%$ of their self-reported scenarios were situated in formal institutional settings such as schools and universities which might normally be considered rather inauthentic settings (Kearney, et al, 2015). This paradox forms the focus for this article which seeks to theorise the concept of authentic learning with mobile technologies. Although authenticity and the learning theories associated with it are often described alongside mobile learning many of the underlying concepts and approaches which have been adopted to enact them as pedagogy are based on a range of assumptions about learning which are rarely articulated or fully explained (Radinsky, et al, 2001, p. 406; Selwyn, 2014).

The paper is structured as follows. Section 2 outlines the background for the paper by exploring why authentic learning is considered important. Section 3 seeks to define the term authentic learning identifying two interpretations which are evident in authentic mobile learning. The main body of the paper (Section 4) brings together existing research about authentic learning to facilitate and support mobile learning. In so doing it identifies three distinct and recurring definitions. These are subsequently presented as vectors in a 3 dimensional orthogonal model which is offered as an original way to conceptualise authentic mobile learning (Section 5). In this final section we discuss the implications of these 
theorisations and consider the utility of the proposed model for better understanding the phenomenon of mobile learning and authenticity.

\section{Why is authentic learning important?}

The concept of authentic learning is not new and may have reached its zenith in Europe during the Middle Ages when it functioned as the primary mode of instruction in the craft guilds where apprentices honed their skills vicariously alongside a master craftsman (Lombardi, 2007, p.6). The advent of industrialisation brought about the need to train a mass labour force meaning the apprenticeship model of learning declined and was supplanted by less direct but more costefficient institutional systems of mass education (Klopfer, Yoon \& Rivas, 2004). Only in recent years has interest in more authentic, real-world learning resurfaced alongside theories of situated learning (Brown, Collins, \& Duguid, 1989) and cognitive apprenticeships (Collins, 1988; Collins, Brown \& Newman, 1989 ). Much of this renewed interest can be traced to economic and technological imperatives which have combined to make authentic learning both economically viable and pedagogically appealing.

The economic drivers stem from the structural shifts in post-Fordist capitalism which have seen the decline in traditional labour intensive industries and the emergence of new forms of production which are largely 'immaterial' in nature, based on the manipulation of networked knowledge and ideas (Lazzarato, 1996; Selwyn, 2014). These structural shifts demand a new set of skills and dispositions for a largely immaterial workforce which include creativity, networking, cooperation and autonomy (Selwyn, 2014).

Technology is also an important driver in the renewed popularity of authentic learning since computers, and more lately mobile technologies have matured to the point at which previously inefficient models of learning are once again feasible. Mobile technologies are relatively ubiquitous, small and discreet making them ideal for many work-based learning tasks such as capturing images, notes and reflections in situ (Burden, Schuck \& Aubusson, 2010). Today's mobile devices are invariably networked which allow learners to participate in real 
communities of practice such as Science Citizen projects where they are supported by genuine professionals, akin to the traditional apprenticeship model, although at a greatly reduced cost.

Given this resurgence of interest in models of authentic learning and the world-wide technological shift to post PC devices (PPD) such as mobile phones and tablet computers, it is timely and important to better understand the assumptions which underpin the concepts of authenticity and mobile learning. Therefore this article addresses the following research questions:

what assumptions underpin the concept of authentic learning with mobile technologies? what functional value do these conceptualisations serve for educators and the wider academic community seeking to further exploit the potential of mobile technologies?

\section{Defining authenticity}

The Oxford dictionary definition of the term authentic reveals two etymological strands upon which similar but significantly different interpretations of the phrase have gradually emerged. In its original form, deriving from the Greek term 'authentikos', authentic is defined as meaning of 'undisputed origin', 'not a copy' or 'replica' and this interpretation has been appropriated into the legal lexicon where synonyms like 'genuineness', 'bona fide' and 'veritable' are used to imply the integrity and originality of a person, object or act.

The second etymological derivation, which has become the more commonly used (at least since the 18th century) stems from a more representative understanding of the term associated with secondary rather than direct experience. An account of an eye witness is described as authentic if it is accurate in its representation of the facts. Authenticity, in this second sense of the term is a measure of reliability and correspondence between the original artefact (e.g. an accident in the street) and its secondary representation (e.g. by an eye-witness). In this secondary interpretation various proxies such as trustworthiness and authoritative certification replace the certainty afforded by direct sensory first-hand presence (Russell, 1959) 
and in this sense authenticity is a measure of fidelity and correspondence between the primary account and its second-hand re-presentation.

When the term authentic is used in association with learning both the direct and representative etymological definitions are invoked but until recently with the emergence of ubiquitous ownership of mobile devices authenticity has most commonly referred to the representative interpretation whereby students tackle real-world problems and challenges through a simulated, rather than a direct participatory interface. Technology and he affordances of mobile technologies, challenge these traditions as will be discussed later in the article.

\section{Authentic learning and mobile technologies}

The term authentic learning is used in various different ways in the field of educational technology and this section explores three different descriptions based on studies of mobile technology use reported in the research literature.

In the first of these authenticity describes the context of the learning activity and the extent to which this is participative or simulated. In these descriptions authenticity is judged by the extent to which students engage in activities and tasks like those undertaken by professional communities of practice in so called 'real world' settings. The second definition relates more to the nature of the tasks and activities undertaken. In these cases authenticity is a measure of the degree of agency granted to students which is also correlated with the extent to which the learning activity is predefined or emergent, planned or unplanned. The third definition of authenticity is embedded within the student's personal goal structures and emotional engagement with the learning activity. From this perspective authenticity is a measure of how far learning activities 'engage students' lived experience, enabling students to find meaningful connections with their current views, understandings and experiences' (Stein, et al, 2004, p. 240). 


\subsection{Unpacking authentic learning}

It is generally agreed that authentic learning ideally requires students to tackle real-world problems located in contexts that mimic the work of professionals and discipline experts (Collins, 1988; Herrington, et al 2008; Lombardi, 2007; Maina, 2004; Renzulli, Gentry, \& Reis, 2004)

'In general, learning environments are considered authentic when there is a similarity between the structured learning activities and some meaningful context for that activity' (Barab, et al, 2000 p.38)

In traditional educational paradigms participative authenticity requires learners to be physically located in the community of practice or professional setting itself as in the apprenticeship model, whereas simulated authenticity allows learners to be located in their normal spaces and contexts where the conditions of the real-world contexts are replicated. Technology blurs these distinctions and mobile technologies are causing them to fracture in ways which are not yet fully understood or appreciated.

\subsubsection{Participatory contexts}

In participative authentic contexts learners participate in genuine real-life communities as 'legitimate peripheral' members (Lave and Wenger, 1991) gradually learning the practices, stories and languages of the community or what has been described as "the ordinary practices of th[at] culture" (Brown, Collins, \& Duguid, 1989, p. 34). In effect learning is a socio-cultural process of identity formation as novices are enculturated into the dominant practices of the community gradually gaining status as experts. Learning is considered to be highly authentic because it is situated in the same context that it will be used making it personally meaningful for the learner.

A practical example using mobile technologies would be use of the sense-it ${ }^{\circledR}$ app which supports learners in measuring and investigating real-world phenomena. It is based on the principles of Citizen Science whereby members of the public use the app on their mobile device 
to collaborate with professional scientists, contributing to observation and measurement data such as species identification and air / water pollution monitoring (Henerodotou, VillasclarasFernández, \& Sharples, 2014). A similar participative project using mobile devices was reported by Scanlon, Woods and Clow (2014) who explain how users of the iSpot application were able to participate in location-based science activities based on the local environment, sharing their findings and data with professional scientists and other activists in an online community of practice.

A simple but highly effective example of participative authenticity is reported by Ebner (2009) who undertook a study of academics using Twitter on their mobile phones as a back channel at an academic conference. Delegates tweeted their responses and impressions of each presentation and these tweets were simultaneously projected on a large screen behind the presenter. In this respect delegates where physically situated in a highly authentic context (the conference) and were also participating in a genuine community of academic practice, as were those lurkers who could not attend the conference directly but could follow and participate online.

In these examples of participative authenticity mobile technologies mediate how learners work alongside professionals gradually acquiring the habits and cultural trappings of the community as in a traditional apprenticeship model. However, in many of these examples the learner does not need to be physically located in the actual community since this can now be achieved through virtual participation even from within a formal setting such as a classroom or conference venue. In this sense mobile technologies are blurring the boundaries or seams between formal and informal learning contexts enabling learners to work in ways which are often described as seamless and unbounded (Looi, Seow, Zhang, So, Chen \& Wong, 2009).

\subsubsection{Simulated contexts}

Previoulsy most authentic learning activities have been simulated in a 'practice field' (Brown, et al, 1989; Collins, et al, 1989) such as the classroom due to the logistical problems associated with direct participation including costs, time and concerns about personal safety. In these 
benign spaces learners simulate the tasks and processes of real-world contexts. Many apps and tools are now available which mimic the tools and processes used by professionals in the realworld such as measurement tools (e.g. virtual wind tunnels, oscilloscopes and laminators) in science. Where these have been used effectively, such as the 'connected classroom' project (Foley \& Reveles, 2014), they use real-world online resources to engage students in authentic but simulated science inquiry. In this example students used handheld devices within the classroom to share data from their own experiments with other students and schools allowing them to compare and analyse across larger data sets and collaboratively identify trends as a community of science learners (Burden and Kearney, 2015).

In a similar case study Jones, Scanlon and Clough (2013) discussed how their nQuire software tool was used on mobile devices to enable science students to take greater responsibility for their own inquiries without adult help. These inquiries were engaging and personally relevant and allowed students to continue their inquiry seamlessly across different contexts such as an after school club and home. These tools and apps have the potential to support highly authentic forms of simulated learning both in formal and hybrid spaces (see below) but empirical research to date suggests they are often used by teachers for low level, unrealistic tasks which bear few resemblances to authentic practices (Kearney, et al, 2012; Kearney et al, 2015).

\subsubsection{Hybrid contexts}

Current advances in mobile technologies have fractured the traditional boundaries between participative and simulated contexts. In some cases this has seen students participating virtually from within formal contexts in genuine and real communities such as the nQuire project described above (Jones, Scalon \& Clough, 2013). In these contexts learning takes on a hybrid complexion which combines features of both a direct, participative and indirect simulated model of authentic learning, and many of the technology projects which have explored these spaces report that they combine all of the best qualities of simulations with the additional benefits of 
high ecological validity acquired through participation in a genuine community.

The combination of Augmented Reality (AR) applications and mobile devices frequently results in hybrid models of authenticity referred to as 'participatory simulations' (Barab \& Dede, 2007). Wong and Looi (2011), for example, documented a series of games played in a physical environment but augmented by virtual artefacts through the mediation of a mobile device ( they called this 'mixed reality learning'). Mobile devices with location-based sensors allowed users in the study to interact with explorations, experiments and challenges for inquiry and games-based learning. Lui, Kuhn, Acosta, Niño-Soto, Quintana and Slotta (2014) described an immersive, cave-like rainforest simulation (called EvoRoom) and a mobile inquiry platform (called Zyeco) that enabled users to collect and share data. Students were co-located in an immersive and physical digital space, collecting observational data from both the classroom itself (Evoroom) and out-of-class settings (such as parks or museums), and exploring peers' data using large visualisations displayed at front of room.

\subsection{Is authentic mobile learning predefined or emergent?}

Despite advances in mobile technologies which have afforded learners greater agency in how they access information, where they situate their learning and how they present the outcomes of this as assessment artefacts, some authors have noted the reluctance of educators to cede significant control of learning to students (Kearney et al., 2015). This is reflected in the extent to which learning is predefined or is left more open ended and emergent in design.

Williams, Karousou and Mackness (2011) define emergent learning as "learning which arises out of the interaction between a number of people and resources, in which the learners organise and determine both the process and to some extent the learning destinations, both of which are unpredictable" (p.3). There is an implicit assumption in many of the studies on authenticity that learning is likely to be more unplanned and emergent than predefined or prescribed when students tackle ill-defined, problems that defy simplistic or quick solutions. Over prescription and unnecessary intervention by educators is included as one of Herrington et 
al's list of inauthentic strategies for mobile learning (2008).

Some researchers have identified planning related to learner generated contexts as a significant vector in understanding how mobile technologies can make learning more authentic (Toh, So, Seow, Chen, \& Looi, 2013). These studies show how students spontaneously used their mobile devices to capture and share images or video clips related to a personal interest or hobby (e.g. bird watching) without the direction or prescription of a teacher or adult (Jones et al, 2013). These examples often occur in informal settings outside of institutional control but there is no reason to suppose this kind of incidental learning with mobile technologies, could not, and is not taking place within formal settings in the form of serendipitous learning (e.g. where a learner uses their mobile device to capture an idea or inspirational thought) (Toh, et al, 2014; Williams, et al 2013).

One area where emergent learning is more evident is in mobile games based applications where players can engage in highly realistic simulations and problem solving exercises that mimic many of the tasks undertaken by real professionals. Gwee, Chee and Tan (2010) reported one such mobile simulation which featured year 9 social studies students using the game Statecraft $\mathrm{X}$ on their iPhones to learn about the concept of governance through role play. What distinguishes the game is the amount of spontaneity and lack of planning. Students worked largely at their own pace without interventions or schedules to regulate them.

These discussions then invite questions as to the extent to which authenticity can or should be designed into the learning experiences of students when they use mobile technologies (Barab, et al, 2000; Petraglia, 1998). This raises an obvious tension as it is difficult to visualise how instructors can design learning activities that are entirely emergent since the very act itself assumes a degree of deliberate intent. For some researchers the solution is to 'deny the legitimacy of preauthentication' altogether by which they mean they reject the notion that designers or teachers can construct predefined authentic tasks, even if these have real and practical use to a genuine community of practice (Barab, et al, 2000). They argue that these 
elements of authentic learning cannot be predefined because they do not guarantee 'buy in' from learners. If the learner does not personally perceive the context to be authentic it cannot be 'preauthenticated' or designed by some other person. In this sense authenticity "is manifest in the flow itself, and is not an objective feature of any one component in isolation" (Barab, et al, 2000, p. 38).

\subsection{Personal commitment of learners}

In considering the nature of authentic learning it is important to identify for whom the learning will be authentic (Barab and Duffy, 2000). Most descriptions of authentic learning describe it from the privileged perspective of the instructor or designer and it difficult to appreciate to what extent learners themselves perceive a learning practice to authentic, or what indeed learners think authentic means. However, ultimately authenticity "lies in the learner perceived relations between the practices they are carrying out and the use value of these practices" (Barab, et al, 2000, p. 38).

This is partly a methodological concern and there is an urgent need for researchers to design more authentic methods and tools which will gain access to this largely missing learner perspective. This is a genuine concern since designing realistic, real world tasks or contexts and processes that mimic or place learners in actual professional communities may count for little if the learner does not perceive these artefacts to have personal significance and meaning in relation to their desired learning objective

"It is very important to consider what is meant by authenticity and to whom - who is the judge (the educator; the learner or the community upon which they try to emulate?)" (Barab \& Duffy, 2000)

Indeed there is a concern amongst some that what constitute genuine real world communities of practice for adults may be far from authentic from the perspective of learners who may speak an entirely separate discourse based on the 'curricular language' with which they are familiar (Heath and McLaughlin, 1994). These critics argue that teachers should 
attempt to locate authentic learning in what they term 'institutions of curricular authenticity' where familiar curricular practices, languages, norms and traditions are the Lingua franca. This position is further supported by Hiebert et al (1996) who argue that students can be engaged in deeply contextualised and authentic tasks within the curriculum as long as they are personally challenged to engage with the underlying concepts and deep structures of the discipline itself.

These considerations therefore foreground a critical third constituent in authentic learning which is the emotional and extra-rational dimension of learning and the commitment of the learner whilst also highlighting one of the more substantial epistemological challenges in the field of authentic learning: how can we capture and understand the learner's emotional sense of engagement and commitment?

"This definition of authenticity correlates how well a learning activity matches a student's personal goal structures (Heath and McLaughlin, 1994) or the extent to which learners themselves problematize the elements that make up the context" ( Stein, et al, 2004, p.

In many of the case studies reported in this paper we can infer that learners were highly motivated and engaged in the mobile learning activities which are described but meaningfulness is a difficult construct to capture and few of the studies detail to what extent the mobile activity enabled learners to develop personal meanings, or indeed why. One exception is the pilot study for the Ecomobile project (Kamarainen et al, 2013). This project explored how the use of a mobile AR application (FreshAIR) could be combined with probeware tools and software to enable students to understand the ecosystem of a pond in ways which resembled real scientific practice. Feedback and video evidence from students undertaking the project indicate that it was highly engaging and had considerable personal significance for students working in their local environment. They appear to have engaged with the topic on a highly personal level despite the fact it did not feature a genuine professional community of scientists as such. 


\section{Discussion and implications}

Derived from the above definitions and examples we propose the following orthogonal model as a means of further conceptualising authentic mobile learning (see figure 1). We identify Context as a critical vector in understanding how and where the learning activity is situated and use the terms 'simulated' and 'participative' as the binaries for this continuum. These are not proposed as normative labels since there is no implication here that either form of authenticity is necessarily more desirable than the other.

The second axis called Planning Design measures the extent to which the learning activity is planned or unplanned in a similar way to the model developed by Toh et al (2013). However, given the emerging affordances of mobile technologies we place greater emphasis on the agency of the learner in co-negotiating and designing these contexts. Hence this vector is used to measure both the degree of agency granted to the learner and the extent to which the learning activity as a whole is preplanned or emergent.

Thirdly we include a vector capturing the Personal Relevance and consequent engagement of the learner since this has emerged across many studies as a highly significant but often neglected element of authentic learning. Unlike the other two vectors which are not normative this vector is more judgemental since it is recognised that learners will elect to disengage from learning which holds little or no personal significance or meaning for them. 


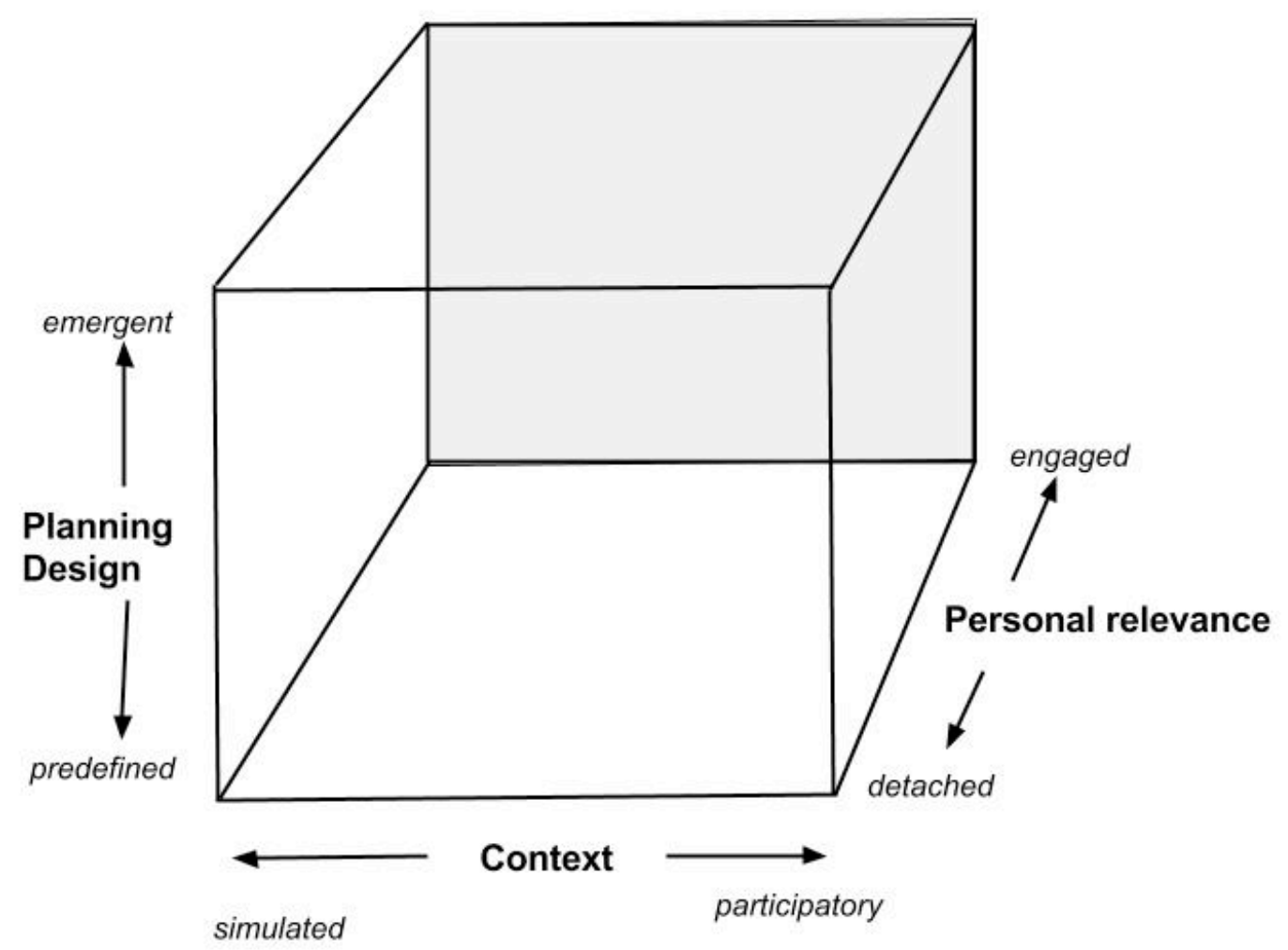

Figure 1. A conceptual model of authentic mobile learning

\subsection{How does the model work?}

To illustrate how this three dimensional model might further support the conceptualisation of authentic mobile learning we have populated it with the three mobile learning scenarios described earlier in the paper represented by the letters A, B and $\mathrm{C}$ (see Figure 2 and Table 1). 


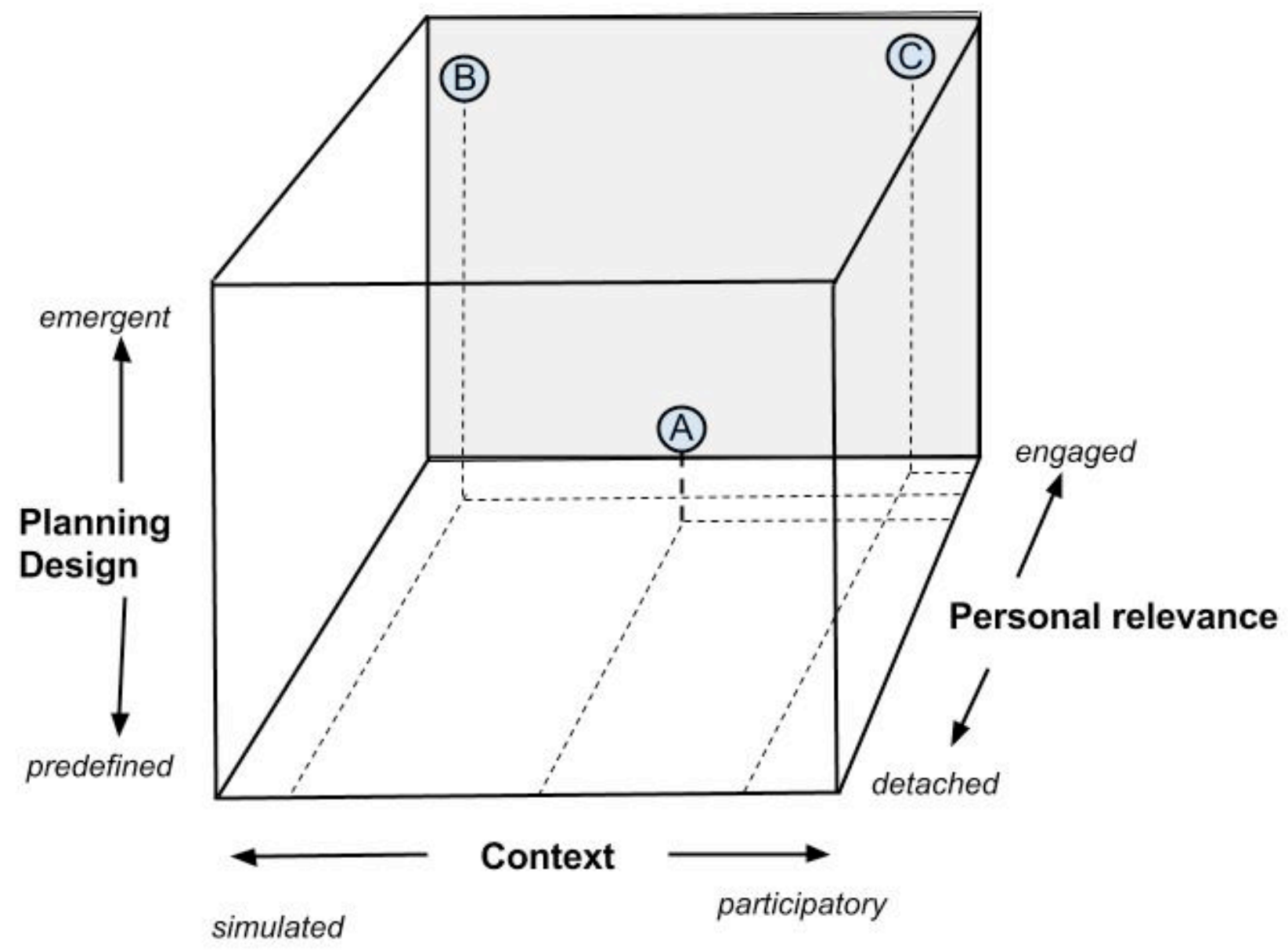

Figure 2. Authentic mobile learning examples

\begin{tabular}{|c|l|c|c|c|}
\hline \multicolumn{1}{|c|}{ Exemplar } & Context & $\begin{array}{c}\text { Planning } \\
\text { Design }\end{array}$ & $\begin{array}{c}\text { Personal } \\
\text { Relevance }\end{array}$ \\
A & $\begin{array}{l}\text { Ecomobile project } \\
(\text { Kamarainen et al, 2013 }\end{array}$ & Hybrid & Predefined & High \\
\hline B & $\begin{array}{l}\text { Statecraft } X \text { mobile learning game } \\
(\text { Gwee }, \text { Chee, and Tan, 2010) }\end{array}$ & Simulated & Emergent & High \\
\hline C & $\begin{array}{l}\text { Twitter back channel in an academic conference } \\
(\text { Ebner, 2009) }\end{array}$ & Participative & Emergent & High \\
\hline
\end{tabular}

Table 1. Characteristics of exemplar authentic mobile learning scenarios 
In terms of the context vector only the Twitter example (C) was classed as participative since it was set in a genuine real world context in this professional learning scenario (an academic conference) accessible in both a physical and virtual manner through the mobile device. In the Ecomobile example (A) students participated in real world tasks and processes using tools in a real-life way and in relevant informal settings but they did not engage with a real community of practice, even though this might have been feasible with the mediation of mobile technology. Therefore the context was identified as a hybrid. The mobile game example (C) was entirely simulated in terms of context since there was little attempt to involve students in a genuine governance community.

Both examples B and C were classed towards the emergent end of the Planning Design spectrum since neither was heavily predefined or structured. In the case of the mobile game (B) students were not restricted by fixed schedules and could engage at their own pace. This was also true in the case of the Twitter example where participants were left to determine how and when they would structure their responses (if at all). The Ecomobile example (A) was more predefined by the teacher who had devised many of the tasks in advance even though most if it occurred in an informal setting outside of school.

Finally, although students were not directly questioned about their levels of personal engagement in any of these three exemplars, we might infer that motivation and engagement was high judging by the amount of activity which occurred, often unsolicited as in the mobile games example, and this suggests all three examples had high personal meaning and significance from the perspective of learners themselves.

\subsection{Returning to research questions}

As shown in even these few examples understanding what is authentic about mobile learning is not straightforward or unproblematic. Therefore this model offers a novel way of conceptualising these issues which rejects simplistic solutions that frame authentic mobile learning in terms of mutually exclusive binaries. Traditionally this is how authentic learning has 
been framed epitomised by the dictionary definition duality between first-hand direct experience which equates with the participatory model of authentic learning, and indirect, second-hand experience which equates to the simulated model of authenticity. This article has argued that this traditional duality is no longer valid when students have access to and use mobile devices, blurring the boundaries between simulated and participative forms of real-world learning, between predefined and emergent models of learning and between high or low levels of personal engagement and meaning making.

The concepts of boundary crossing and boundary objects which are inherent features of Activity theory (Engeström, Engeström \& Kärkkäinen, 1995) are useful ways of thinking about authenticity and mobile learning because they focus on learning which transcends conventional boundaries such as home/school, formal/informal, physical/virtual using mobile devices as cultural objects which mediate these crossings. Here, "boundaries are understood as a social cultural difference between systems, practices, or social worlds, leading to a discontinuity in action or interaction between these systems" (Snoek, 2013, p.309). In effect mobile devices fulfil a bridging action since they enable learners to cross traditional boundaries such as the student who joins an authentic community of scientists on Twitter posting and following tweets as a legitimate member of the community, but from within a formal classroom setting which would traditionally be bounded both physically and culturally in such a manner that this was not feasible. Whilst the mobile device acts as a boundary crossing object in these cases it does so within culturally defined boundaries and practices of the traditional classroom setting. If the teacher, and indeed the institution, prohibit the use of technology across contexts in this seamless fashion (Jones, et al, 2013; Wong, Milrad \& Specht 2015), or if they attempt to pre authenticate or overly predefine the learning outcomes, it is unlikely these opportunities to cross boundaries will be ceased upon, or alternatively they become a form of subversive activity undertaken by students looking to escape the rigidity and sterility of learning.

What this chapter has also attempted to highlight is the primacy of affective factors such as perceptions of personal relevance on the part of the learner which is so critical in 
authentic learning. Research in the pre-mobile era already suggested that authenticity was not a commodity which could be objectified and designed into the context or tasks itself (Barab, et al, 2000) but rather it was highly ephemeral and closely associated with the personal perceptions of the individual learner. Current research into authentic mobile learning has identified a significant list of characteristics that are deemed to make learning more authentic (Herrington et al, 2008) but there is little empirical evidence of what these factors mean from the perspective of learners themselves. There is an urgent need, therefore, for the mobile learning research community to better understand how this kind of data might be elicited and how it would then be used to support in the design of more meaningful and engaging authentic mobile learning scenarios. In this respect we still face the same epistemological and methodological challenges that were highlighted by researchers investigating the potential of first generation computers to enhance authentic learning:

"A major challenge for instructional designers is to develop learning environments that incorporate authentic tasks in realistic contexts" (Barab, et al, 2000, p.60)

\section{Conclusion}

At the beginning of this paper we identified a conundrum which questioned why educators associate mobile learning so closely with authenticity if most of their learning tasks are situated in formal settings such as schools and universities? The paper has posited that no single criteria or characteristic makes a learning activity authentic (Banas \& York, 2014) and it has also argued that traditional definitions of authenticity are in need of revision and upgrade to better reflect the boundary crossing potential mediated by mobile devices. Although formal settings such as schools and universities might once have been considered contrived contexts for learning compared to genuine real world-settings such as work placements or apprenticeship this definition is rooted in pre-mobile notions of space and time (Traxler, 2009) which are no longer as applicable as they were previously. The conceptual model proposed in this chapter (see Figure 1) has a practical orientation for learning design in mobile environments since it 
highlights three critical vectors that need to be considered carefully in order to maximise the authenticity of any mobile learning experience. Futher research is also required to investigate to what extent educators and learners are reconceptualising their thinking about authentic learning when mobile devices are used seamlessly cross the traditional boundaries between formal and informal contexts, virtual and physical worlds and planned and emergent spaces. This paper offers a model to initiate and support this process.

\section{References}

Banas, J., \& York, C (2014). Authentic learning exercises as a means to influence preservice teachers' technology integration self-efficacy and intentions to integrate technology Australasian Journal of Educational Technology, 30(6).

Barab, S. A., \& Dede, C. (2007). Games and immersive participatory simulations for science education: an emerging type of curricula. Journal of Science Education and Technology, 16(1), 1-3 doi: 10.1007/s10956-007-9043-9.

Barab, S. A. \& Duffy, T.M. (2000). From Practice Fields to Communities of Practice, In Jonassen, D.H \& Land, S.M (Eds), Theoretical Foundations of Learning Environments, (pp. 25-55). Mahwah, N.J: Erlbaum Associates.

Barab, S. A., Squire, K. D., \& Dueber, W. (2000). A co-evolutionary model for supporting the emergence of authenticity. Educational Technology Research and Development, 48(2), $37-62$.

Brown, J.S., Collins, A., \& Duguid, P. (1989). Situated cognition and the culture of learning. Educational Researcher, 18 (1), 32- 42

Burden, K., Aubusson, P \& Schuck, S. (2010). Ethical professional mobile learning for teaching and nursing workplaces. Chapter 12, in Pachler, N., Pimmer, C., \& Seipold, J. (Eds), Work-based Mobile Learning: Concepts and Cases. A Handbook for Academics and Practitioners (pp. 277-305). Oxford: Peter Lang.

Burden, K., \& Kearney, M. (Under review). Future Scenarios for Mobile Science Learning, Research in Science Education, 44 (3) 
Collins, A. (1988). Cognitive apprenticeship and instructional technology. (Technical Report No. 6899). Cambridge, MA: BBN Labs Inc.

Collins, A., Brown, J. S. \& Newman, S. E. (1989). Cognitive apprenticeship: teaching the crafts of reading, writing and mathematics. In L. B. Resnick (Ed.), Knowing, Learning and Instruction: Essays in Honor of Robert Glaser (pp. 453-494). Hillsdale: Erlbaum.

CTGV (Cognition and Technology Group at Vanderbilt) (1990). Technology and the design of generative learning environments. Educational Technology, 31(5), 34-40.

Ebner, M. (2009). Introducing live microblogging: how single presentations can be enhanced by the mass. Journal of Research in Innovative Teaching, 2(1), 91-100.

Engeström, Y., Engeström, R. \& Kärkkäinen, M. (1995). Polycontextuality and boundary crossing in expert cognition: Learning and problem solving in complex work activities. Learning and Instruction, 5(4), 319-336.

Foley, B. J., \& Reveles, J. M. (2014). Pedagogy for the Connected Science Classroom: Computer Supported Collaborative Science and the Next Generation Science Standards. Contemporary Issues in Technology and Teacher Education, 14(4), 401-418.

Gwee, S., Chee, Y. S., \& Tan, E. M. (2010). Game play-time and learning outcomes of boys and girls in a social studies mobile game-based learning curriculum. In M. Montebello, V. Camilleri, \& A. Dingli (Eds.), Proceedings of the 9th International Conference on Mobile Learning (pp. 16-23). Valletta, Malta: University of Malta.

Heath, S. B. \& Mclaughlin, M. W. (1994) Learning for anything everyday. Journal of Curriculum Studies, 26(5), 471-489.

Herrington, J., \& Kervin, L. (2007). Authentic learning supported by technology: Ten suggestions and cases of integration in classrooms. Educational Media International, 44(3), 219-236.

Herrington, J., Mantei, J., Herrington, A,. Olney I., \& Ferry, B. (2008). New technologies, new pedagogies: Mobile technologies and new ways of teaching and learning. In Hello! Where are you in the landscape of educational technology? Proceedings ascilite 
Melbourne 2008. Retrieved on $4^{\text {th }}$ February 2015, from

http://www.ascilite.org.au/conferences/melbourne08/procs/herrington-j.pdf

Herrington, J., \& Oliver, R. (2000). An instructional design framework for authentic learning environments. Educational Technology Research and Development, 48(3), 23-48.

Hiebert, J., Carpenter, T.P., Fennema, E., Fuson, K., Human, P., Murray, H, Olivier, A \& Wearne, D. (1996). Problem solving as a basis for reform in curriculum and instruction: the case of mathematics. Educational Researcher, 25(4), 12-21

Herodotou, C., Villasclaras-Fernández, E., \& Sharples, M. (2014). The Design and Evaluation of a Sensor-Based Mobile Application for Citizen Inquiry Science Investigations. In Open Learning and Teaching in Educational Communities (pp. 434-439). Springer International Publishing.

Jones, A. C., Scanlon, E., \& Clough, G. (2013). Mobile learning: Two case studies of supporting inquiry learning in informal and semiformal settings. Computers \& Education, 61, 21-32.

Kamarainen, A. M., Metcalf, S., Grotzer, T., Browne, A., Mazzuca, D., Tutwiler, M. S., $\&$ Dede, C. (2013). EcoMOBILE: Integrating augmented reality and probeware with environmental education field trips. Computers \& Education, 68, 545-556.

Kearney, M., Burden, K., \& Rai, T. (2015). Investigating teachers' adoption of signature mobile pedagogies. Computers \& Education, 80, 48-57

Kearney, M., Schuck, S., Burden, K., \& Aubusson, P. (2012). Viewing mobile learning from a pedagogical perspective. Research in Learning Technology, 20, 14406

DOI: $10.3402 /$ rlt.v20i0/14406

Klopfer, E., Yoon, S., \& Rivas, L. (2004). Comparative analysis of Palm and wearable computers for participatory simulations. Journal of Computer Assisted Learning, 20, 347-359. doi:10.1111/j.1365-2729.2004.00094.x

Lave, J., \& Wenger, E. (1991). Situated Learning: Legitimate Peripheral Participation. Cambridge University Press: Cambridge 
Lazzarato, M. (1996). “Immaterial Labour.” In M. Hardt \& P. Virno (Eds), Radical Thought in Italy: A Potential Politics (pp.133-47). University of Minnesota Press: Minneapolis

Lombardi, M. M. (2007). Authentic learning for the 21st Century: An Overview. Educause Learning Initiative Report No. 1, Boulder, CO, EDUCAUSE Learning Initiative. Retrieved on $5^{\text {th }}$ June 2015, from http://www.educause.edu/ir/library/pdf/ELI3009.pdf.

Looi, C.-K., Seow, P., Zhang, B., So, H.-J., Chen, W. \& Wong, L.-H. (2010), Leveraging mobile technology for sustainable seamless learning: a research agenda. British Journal of Educational Technology, 41, 154-169. doi: 10.1111/j.1467-8535.2008.00912.x

Lui, M., Kuhn, A., Acosta, A., Niño-Soto, M. I., Quintana, C., \& Slotta, J. D. (2014) Using mobile tools in immersive environments to support science inquiry. In CHI'14 Extended Abstracts on Human Factors in Computing Systems (pp. 403-406). ACM.

Maina, F. W. (2004). Authentic learning: Perspectives from contemporary educators. Journal of Authentic Learning, 1(1), 1-8.

Meyers, N., \& Nulty, D. (2009). How to use (five) curriculum design principles to align authentic learning environments, assessment, students' approaches to thinking and learning outcomes. Assessment \& Evaluation in Higher Education, 34(5), 565-577. doi: $10.1080 / 02602930802226502$

Petraglia, J. (1998). Reality by design: The rhetoric and technology of authenticity in education. Mahwah, NJ: Lawrence Erlbaum Associates.

Radinsky, J., L. Bouillion, E. Lento, \& L. Gomez. (2001). Mutual benefit partnership: A curricular design for authenticity. Journal of Curriculum Studies, 33(4), 405-430.

Renzulli, J. S., Gentry, M., \& Reis, S. M. (2004). A time and a place for authentic learning. Educational Leadership, 62(1), 73-77.

Russell, B. (1959). The Problems of Philosophy. (New ed.). London: Oxford University Press. 
Scanlon, E., Woods, W., \& Clow, D. (2014). Informal Participation in Science in the UK: Identification, Location and Mobility with iSpot. Journal of Educational Technology \& Society, 17(2), 58-71.

Selwyn, N. (2014). Distrusting Educational Technology: Critical Questions for Changing Times. New York: Routledge

Snoek, M. (2013). From splendid isolation to crossed boundaries? The future of teacher education in the light of activity theory. Teacher Development,17(3), 307-321

Stein, S. J., Isaacs, G., \& Andrews, T. (2004). Incorporating authentic learning experiences within a university course. Studies in Higher Education, 29(2), 239-258.

Toh, Y., So, H. J., Seow, P., Chen, W., \& Looi, C. K. (2013). Seamless learning in the mobile age: a theoretical and methodological discussion on using cooperative inquiry to study digital kids on-the-move. Learning, Media and Technology, 38(3), 301-318.

Traxler, J. (2009). Learning in a mobile age, International Journal of Mobile and Blended Learning, 1(1), 1-12

Williams, R., Karousou, R., \& Mackness, J. (2011). Emergent learning and learning ecologies in Web 2.0. International Review of Research in Open and Distance Learning $12(3) \mathrm{np}$

Wong, L.H., \& Looi, C.K. (2011). What seams do we remove in mobile assisted seamless learning? A critical review of the literature. Computers and Education, 57(4), 23642381

Wong, L.H, Milrad, M \& Specht, M. (2015) (Eds). Seamless Learning in the Age of Mobile Connectivity. Singapore: Springer. 